SPECIAL ISSUE: ARTICLE

Lab and Field Experiments

\title{
An experimental comparison of rebate and matching in charitable giving: The case of Japan
}

\author{
Shusaku Sasaki ${ }^{1,3} \cdot$ Hirofumi Kurokawa ${ }^{2} \cdot$ Fumio Ohtake ${ }^{3,4}$
}

Received: 14 May 2021 / Revised: 12 July 2021 / Accepted: 12 July 2021 /

Published online: 16 August 2021

(C) The Author(s) 2021

\begin{abstract}
This study uses a Japanese nationwide sample and experimentally compares rebate and matching, both of which are schemes intended to lower the price of monetary donation. Standard economic theory predicts that the two schemes will have the same effect on individuals' donation behavior when their donation price is equivalent. However, we conduct an incentivized economic experiment through the Internet on 2300 Japanese residents, and find that matching, which lowers the donation price by adding a contribution from a third-party, increases individuals' donation expenditures compared to rebate, which lowers it through a refund from a thirdparty. The experimental result shows that the donation expenditure in a $50 \%$ rebate treatment drops by approximately 126 Japanese yen compared to the control, while in a 1:1 matching treatment with essentially the same price of donation as the $50 \%$ rebate, the expenditure conversely rises by approximately 56 Japanese yen. This tendency is consistent with the results of previous experimental studies comparing the two schemes. We further empirically confirm that the superiority of 1:1 matching over $50 \%$ rebate is not conclusively influenced by the participants' confusion or misunderstanding, or budget constraint lines' difference between the two schemes. Although the Japanese government has previously enriched rebate's content, the level of monetary donations by the Japanese people is still low on an international scale. Based on this study's findings, we discuss the possibility that implementing matching into the society effectively encourages their donation behavior.
\end{abstract}

Keywords Charitable subsidy · Tax incentive $\cdot$ Framing effect $\cdot$ Behavioral economics $\cdot$ Online experiment

JEL D91 $\cdot \mathrm{H} 20 \cdot \mathrm{C} 90$

Shusaku Sasaki

ssasaki.econ@gmail.com

Extended author information available on the last page of the article 


\section{Introduction}

Non-profit organizations are essential for social stability, since they provide complementary services in fields where public services are not sufficiently provided by governments (Salamon, 1994). The NPOs depend on donations from individuals and corporations to continue their operations. Thus, the question of how to effectively collect those donations is an important social issue, and it has been explored both practically and academically (Sargeant \& Shang, 2017).

A number of countries have adopted rebate as a major scheme with the aim of encouraging monetary donations from individuals (Giving Japan White Paper Research Society, 2017). Under this scheme, individuals' income tax is deducted by a certain amount, when they report the monetary donations they made in the year when declaring their income for that year. Policymakers expect the scheme to have a positive effect on individuals' donation behavior, because it lowers the price of donation. For example, assume one donates 10,000 Japanese yen (JPY, hereafter) to a charity and receives a tax reduction of $5000 \mathrm{JPY}$; this implies that one can donate 10,000 JPY to the charity by spending only $5000 \mathrm{JPY}$, and the price of $1 \mathrm{JPY}$ donation is $0.5 \mathrm{JPY}$.

However, rebate may not induce as much donation behavior as policymakers expect. Institutional and procedural hurdles can impede donors' use of the scheme. For example, the US tax system allows taxpayers to select either a standard deduction or an itemized deduction, the latter of which is an actual deduction. Only if they select the latter, they can have access to the rebate scheme. In practice, high-income taxpayers usually choose the itemized deduction, while about $70 \%$ of taxpayers choose the standard one. Thus, many US donors do not enjoy the benefits of the rebate scheme (Kato, 2010).

Matching is another major scheme used to lower the price of donation, similar to rebate. Previous experimental economic studies have suggested that matching encourages individuals' donation behavior more effectively than rebate. When one donates 5000 JPY to a charity under a 1:1 matching treatment, a third party, for example a corporation or foundation, matches the amount of this donation, and consequently 10,000 JPY is donated to the charity. In other words, one needs to spend only $5000 \mathrm{JPY}$ to donate 10,000 JPY to the charity, and the price of 1 JPY donation is $0.5 \mathrm{JPY}$ in a 1:1 matching. This is the same as when one donates 10,000 JPY under the rebate scheme and receives a refund of $5000 \mathrm{JPY}$ in the form of a tax reduction. However, even when controlling for the donation price and other factors, laboratory experiments have found that the matching framing increases donation rates and average donation expenditures more than the rebate framing (Eckel \& Grossman, 2003, 2006). This tendency has been confirmed in field experiments (Bekkers, 2015; Eckel \& Grossman, 2008, 2009, 2017). Based on this evidence, the matching scheme is now being employed in fundraising activities by NPOs around the world.

This study is the first to experimentally compare the rebate and matching schemes in Japan, and to test whether matching is more effective in driving individuals' donations in this country. We are now conducting the investigation 
in Japan even though there is evidence from other countries, because there are background and environmental factors at play that suggest that the rebate scheme might not be effective in promoting donation behavior in Japan either. In other words, there is a great need to explore another measure that can more effectively encourage Japanese people's donation behavior.

First, although the Japanese government has made efforts to improve the rebate scheme, its utilization rate remains low, and the level of individual donations in Japan is also low on an international scale. The Japanese government introduced rebate as a tax incentive in 1962, with this scheme in force since over than half a century. The 2011 tax reforms enabled individual donors to select "exemption and deduction from income" or "tax credit," which are called "shotoku-kojyo" and "zeigaku-kojyo" in Japanese, respectively (Cabinet Office, 2019a). When the former is selected, $2000 \mathrm{JPY}$ is deducted from one's donation amount, and that amount is then deducted from one's income. The income after the deduction is multiplied by an income tax rate to calculate one's income tax. Japan's income tax rates follow a progressive system, and therefore the tax reduction for the same donation amount is larger for higher income groups. In contrast, when the latter is selected, 2000 JPY is deducted from one's donation amount, that amount is multiplied by $40 \%$, and then the amount after multiplication is directly deducted from one's income tax, regardless of income groups. Therefore, low- and middle-income groups can receive a larger tax reduction by selecting the tax credit option over exemption and deduction from income. ${ }^{1}$ Countries offering both systems are rare, and, in this sense, Japan's rebate scheme is progressive on an international scale. However, the proportion of Japanese donors using the rebate remains low and was recorded at $16.7 \%$ in 2018 (Cabinet Office, 2019b). Furthermore, as is widely known, the level of individual donations in Japan is much lower than in other countries. Specifically, the total value of individual donations in Japan stood at $0.14 \%$ as a share of nominal GDP in 2016. This is only about one-tenth of the US donations (1.44\%), about one-quarter of that of the UK $(0.54 \%)$, and about one-quarter of that of South Korea $(0.50 \%)$, which is also an East Asian nation (Giving Japan White Paper Research Society, 2017). This raises the concern that the past improvements to the rebate scheme have not had enough impact on promoting Japanese people's donation behavior.

Second, the cost of using the rebate in Japan could be as high as or higher than in other countries. In Japan, individual income tax is withheld at source, and the income taxes of employed income earners are recalculated in December by their employers to correct any excess or deficiency. Thus, many Japanese workers usually do not need to file tax returns; however, they would need to do so to make use of the rebate scheme. Using the scheme would impose a psychological cost on people

\footnotetext{
1 Imagine that a person with a taxable income of 6,000,000 JPY donates 50,000 JPY. When the person chooses the exemption and deduction from income, the refund will be 9600 JPY. On the other hand, when the person chooses the tax credit, the refund will be 19,200 JPY.
} 
because of performing an unfamiliar task, in addition to procedural costs. These costs could discourage people from making donations by using the rebate scheme. ${ }^{2}$

Matching increases the amount donated to a charity by combining the donation amounts of donors with that of a third party. Since the charities or the third party are usually responsible for the add-on donation process, donors' procedural and psychological costs will be smaller when using matching than when using rebate. Thus, if matching is confirmed through experiments to be more effective than rebate in Japan, there is a potential to substantially increase donations made by Japanese people, by implementing the matching scheme into the society. However, to the best of our knowledge, there have been no experimental studies directly comparing matching and rebate in Japan. ${ }^{3}$ This study is quite important from both an academic and a policy perspective in that it is the first to conduct such an experimental comparison in this country.

The remainder of this paper is structured as follows. "Literature review on rebate versus matching" reviews experimental studies in economics that have compared rebate and matching schemes. "Experimental design" describes the experimental design in this study. Following basic results in "Basic analysis", we conduct and present further analysis in "Further analysis". "Discussion, limitations and conclusions" discusses the results and their practical implications and concludes while noting some limitations.

\section{Literature review on rebate versus matching}

Eckel and Grossman (2003) point out that a matching rate $(m)$ is a function of a rebate rate $(r)$ as follows: $m=r /(1-r)$. This formula shows that a 1:1 matching is equivalent to a $50 \%$ rebate. In the former scheme, when one chooses to donate 5000 JPY to a charity, the same amount will be added to this donation, thus making the total amount donated to the charity 10,000 JPY. In the latter scheme, when one chooses to donate 10,000 JPY to a charity, half of the amount will be refunded, making the actual donation expenditure 5000 JPY. Similarly, a 2:1 matching is equivalent to a $33 \%$ rebate, and a $4: 1$ matching is equivalent to a $20 \%$ rebate. $^{4}$

Standard economic theory predicts that, when the donation price and all other factors are equal, there should be no difference in individuals' donation behavior under

\footnotetext{
2 According to data released by the by Cabinet Office (2019b), $13.4 \%$ of Japanese donors who did not use the rebate scheme in 2018 stated that it is because they did not file tax returns. This is the third major reason for not using the scheme. The top reason is that they did not know about this scheme (40.9\%).

${ }^{3}$ In Japan, the possibility that rebate promotes donation behavior has been a subject of economic examination (Yamauchi, 1997): however, again, there have been no experimental studies directly comparing rebate and matching.

${ }^{4}$ We find in the comparison of consumption and income taxes, another example of people's different reactions under two essentially equivalent conditions. When all income goes to consumption, the relationship between the income tax rate $(y)$ and the consumption tax rate $(c)$ is as follows: $y=c /(1+c)$. Blumkin et al. (2012) show that subjects decrease their labor supply under an income tax system more than the equivalent consumption tax system. Kurokawa et al. (2020) show that subjects prefer an income tax over the equivalent consumption tax.
} 
matching and rebate schemes. However, Eckel and Grossman (2003) reveal that donation rates and average donation expenditures for matching are higher than for rebate, by employing a within-subject design where subjects are randomly exposed to both the schemes. Eckel and Grossman find similar results in 2006, when using a between-subject design where subjects are exposed to only one of the two schemes. Furthermore, this superiority of matching over rebate has been confirmed in multiple field experiments (Bekkers, 2015; Eckel \& Grossman, 2008, 2009, 2017).

Thus, the relative effectiveness of matching has been robustly observed in various experimental studies; however, there exist debates on why matching can drive individuals' donation behavior more effectively than rebate, and some researchers have conducted multifaceted investigations. Eckel and Grossman argue that this tendency can be explained by framing effect (Lukas et al., 2010). Specifically, matching has a "cooperative framing." Within this frame, since people can additionally gain a conformity utility by collaborating with others to donate, they will be more likely to donate. In contrast, rebate has a "reward framing." Within this frame, particularly for individuals with warm glow (Andreoni, 1989, 1990), receiving a refund will reduce their selfish utility of donating to a charity themselves. In other words, receiving a refund causes them to feel "greedy" (Benabou \& Tirole, 2006), and they will be less likely to donate.

However, other researchers raise the concern that the superiority of matching can be explained by people's confusion or misunderstanding rather than by framing effect (Davis \& Millner, 2005; Davis et al., 2005). They conjecture whether subjects in previous experiments may have incorrectly understood how each scheme works and the differences between them, and whether they may have chosen the same amount to be passed on to a charity in both schemes without deliberation, resulting in higher donation expenditures under matching than those after refund under rebate. Davis (2006) also proposes "isolation effect," which implies that when individuals face a complex problem, they often only consider factors that they directly have control over or that have direct consequences for them. However, Eckel and Grossman have addressed other researchers' concerns, by employing a between-subjects design where subjects face only one of the two schemes, by providing in advance calculation exercises to support their understanding for the assigned scheme, by checking afterward their understanding of the experiment, and by providing information on all combinations of "initially selected amount," "reward to self," and "donated amount to the charity," to make their decisions more transparent. Then, Eckel and Grossman argue that the superiority of matching over rebate is still due to framing effect rather than their misunderstanding or confusion.

Furthermore, Blumenthal et al. (2012) note that in Eckel and Grossman's (2003, 2006) experimental designs, the matching and rebate rates are equivalent, while the budget constraint lines are not completely equivalent between the two schemes. Specifically, the budget constraint lines' slopes are the same between the two schemes, but the rebate's line is partly truncated (See the Figure Appendix A). For example, people who would spend 1000 JPY on a donation in the control can spend only 500 JPY in a 50\% rebate. Even if they select the same initial amount of 1000 JPY, 50\% of that amount is refunded to them. If they are assigned to a 1:1 matching, they can maintain the same 1000 JPY donation expenditure. Similarly, the $50 \%$ rebate allows 
subjects to select an amount donated to charity of between 0-1000 JPY only, while the 1:1 matching allows them to select the amount between 0 and 2000 JPY. However, more recent experiments by Lukas et al. (2010) and Blumenthal et al. (2012) unify budget constraint lines, by allowing subjects in the rebate to increase their maximum contribution amount or constraining that of subjects in the matching, and still confirm some superiorities of matching over rebate. ${ }^{5}$

The purpose of this study is to clarify and confirm the difference in effectiveness between rebate and matching to determine the validity of the strategy for implementing matching schemes in Japan. Although it is unlikely that this study's results directly contribute to concluding the above debates over the mechanisms, the debates must be considered when constructing our experimental design and interpreting our experimental results. As we will show the details in the following section, our experiment can identify the subjects with confusion or misunderstanding. We further interpret our experimental results while empirically considering the impact of differences in budget constraint lines between the two schemes.

\section{Experimental design}

\subsection{Overview}

Between March 19 and March 21, 2019, we conducted an economic experiment through MyVoice.com Ltd., which offers online surveys and experiments. Around 1 million adults living throughout Japan register the company as response monitors. We sampled 2300 participants from these monitors in equal proportions by gender and age (age range: 20 and 69 years).

The experiment in this study is incentivized using "points," which can be exchanged for gift cards (nationwide gift cards, Amazon gift cards, App Store \& iTunes gift cards, book cards, etc.) (MyVoice.com Ltd., 2020). The participants receive 70 points by answering the survey and can earn additional points, which vary depending on their choices in the experiment, as explained in the next section. Note that the exchange rate is 1 point $=1 \mathrm{JPY}^{6}$

The structure of this survey and experiment can be divided into three main parts (Fig. 1). First, we present the participants with questions that capture their behavioral economic characteristics, including social, time, and risk preferences. ${ }^{7}$ Second, we randomly divide them into rebate treatments, matching treatments, or a control, and conduct the economic experiment to capture their donation behavior under each assigned condition. Specifically, we construct two groups, respectively, for the rebate treatments $(50 \%$ rebate and $20 \%$ rebate) and the matching treatments

\footnotetext{
5 Other recent studies have proposed new theoretical explanations for the difference between matching and rebate (Diederich et al., 2020; Hungerman and Ottoni-Wilhelm, 2021).

6 One US dollar was approximately equivalent to 111 Japanese yen in March 2019.

7 Our questions about social, time, and risk preferences are based on the Global Preference Survey (Falk et al., 2018).
} 


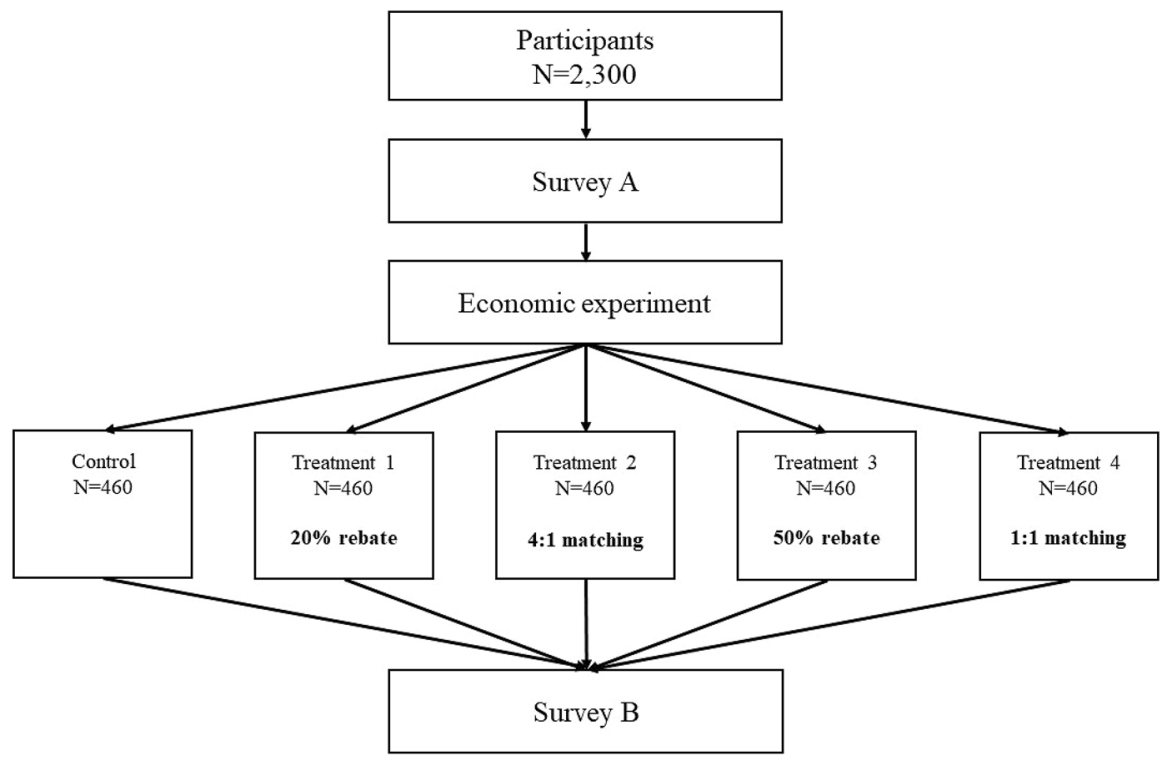

Fig. 1 The survey and experimental structure

(1:1 matching and 4:1 matching). Third, we present participants with questions to capture their socioeconomic attributes, including gender, marital status, number of children, years of education, household income, place of residence, etc., and gather their responses. ${ }^{8}$

\subsection{Procedures}

In the introductory page to the experimental part of the survey, participants are informed that, in addition to the basic reward points for answering the survey, one in ten will have a chance to earn another reward (See the Figure Appendix B). ${ }^{9}$ They are also informed that the additional reward points are worth $1000 \mathrm{JPY}$, and that the following page will ask how much of the 1000 JPY they are willing to pass on

\footnotetext{
${ }^{8}$ Although this study falls outside the scope of the Japanese government's Ethical Guidelines for Medical and Health Research Involving Human Subjects and thus did not receive an ethical review, all participants gave their informed consent to participate in our survey experiment. After being informed about the purpose of the study and their right to withdraw from the survey, they agreed to join. They were provided with the option "I want to stop participating in the survey" for all the questions. Completion of the entire survey experiment was considered to indicate respondent consent. The authors did not obtain any personal information about the participants.

${ }^{9}$ Charness et al. (2016) review incentive schemes for laboratory experiments and report that there is no significant difference for experimental results between the schemes where incentives are paid to all participants, and the other schemes where incentives are randomly paid to a part of the participants.
} 
to a social contribution project, assuming they could win and earn this additional reward. ${ }^{10}$

Here, to help the participants understand that this experiment is not hypothetical but that they will receive a real monetary reward, we set the following checkbox confirmations: "If you win and earn 1000 JPY, your donation decision will be carried out as you answer," "After winning, you cannot change your answer. So, please think carefully before answering," and "If you do not win, you will not earn 1000 JPY, but your donation decision will not be carried out either." The participants have to confirm all the checkboxes to proceed to the following page. By implementing the above device, we ensure the incentive compatibility of their choices.

Following this, regardless of the randomly assigned groups, the participants see the following message and are requested to donate to an organization engaged in afforestation activities. ${ }^{11}$

"Afforestation activities are currently being carried out around the world in order to reduce carbon dioxide emissions and prevent global warming. Your donation will help to support an organization engaged in the afforestation activities. Your donation will be used by the organization to restore rainforests in countries, including Indonesia, Myanmar, and Vietnam. Your generous support is greatly appreciated."

In addition to the above message, the survey screen for the participants in the four groups of rebate and matching display an "Important Notice," which informs them of the content of the assigned treatment (Fig. 2).

Table 1 briefly summarizes how each group works. When one initially selects the option to pass on A to the organization in the control group, the actual donation expenditure is A, the reward to oneself is $1000 \mathrm{JPY}-\mathrm{A}$, and the donated amount to the organization is A. Table 1 shows a calculation example when A is 500 JPY in the control group. Next, by comparing the formulae for each treatment group and calculation examples, we understand that, in the price of donation, a 20\% rebate and a 4:1 matching are equivalent and a 50\% rebate and a 1:1 matching are equivalent. Specifically, when one initially selects 1000 JPY in a $20 \%$ rebate, 1000 JPY is donated to the organization, while the individual will receive a refund of 200 JPY, making the actual donation expenditure $800 \mathrm{JPY}$. If one initially selects $800 \mathrm{JPY}$ in a 4:1 matching, with the 200 JPY additional contribution, the donated amount to the organization becomes $1000 \mathrm{JPY}$. The two cases are identical in the price of donation. If the

\footnotetext{
10 Since the additional reward of $1000 \mathrm{JPY}$ is paid to one person out of ten, its expected value is 100 JPY. According to "Giving Japan 2017" (Giving Japan White Paper Research Society, 2017), the median amount of Japanese people's donation is a few thousand Japanese yen. Using the incentive scheme of random payment, we allow participants to choose their donation amount from the endowment, which is close to that in the real world. Our analyses empirically address the concern that the random payment may influence the estimated results by controlling for the effect of participants' risk attitude.

11 Before the experiment, we contacted the organization and obtained their approval for selecting them as the recipient. To ensure the recipient's credibility, we selected the recipient among specified publicservice promotion corporations, which are designated by a cabinet order as ones that significantly contribute to the promotion of public interest.
} 
$20 \%$ rebate:

Important Notice:

For every donation amount you pass on to the charity, the experimenter will refund $20 \%$ of the amount to you.

\section{4:1 matching:}

Important Notice:

For every donation amount you pass on to the charity, the experimenter will match it with an additional $25 \%$ of the amount.

$50 \%$ rebate:

Important Notice:

For every donation amount you pass on to the charity, the experimenter will refund $\mathbf{5 0} \%$ of the amount to you.

\section{1:1 matching:}

Important Notice:

For every donation amount you pass on to the charity, the experimenter will match it with an additional equal amount.

Fig. 2 Treatment messages

initial selection is $1000 \mathrm{JPY}$ in a 50\% rebate, $1000 \mathrm{JPY}$ is donated to the organization, while the individual will receive a refund of $500 \mathrm{JPY}$, making the actual donation expenditure $500 \mathrm{JPY}$. If the initial donation is $500 \mathrm{JPY}$ in a 1:1 matching, 


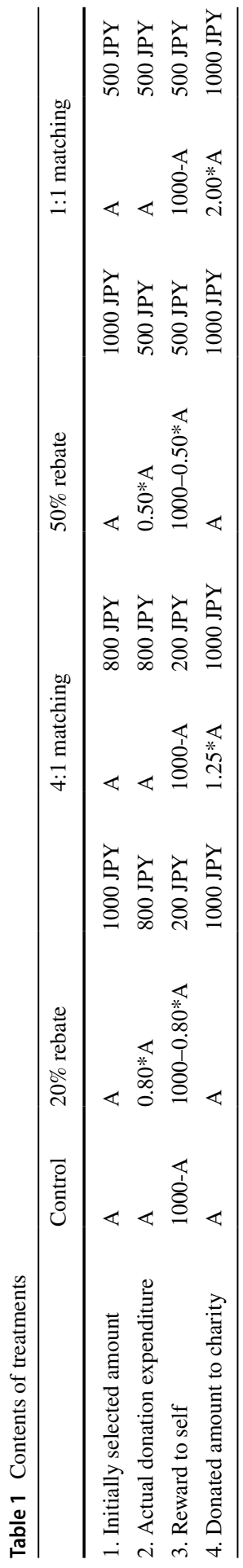


with the 500 JPY additional contribution, the donated amount to the organization becomes 1000 JPY. Once again, the two cases are identical in the price of donation.

Finally, all the participants are asked;

"If you win and earn 1000 JPY, how much of the 1000 JPY are you willing to pass on to the worldwide afforestation activities? Please answer in increments of 100 JPY."

Participants are required to initially select the amount to pass on to the organization between 0 JPY and 1000 JPY.

Even after the participants read their treatment message, it may be still difficult for them to correctly understand the relationship between the "initially selected amount," "reward to self," and "donated amount to the charity." If many of the participants do not understand this relationship, their selections will be due not to framing effect as proposed by Eckel and Grossman, but rather due to their confusion or misunderstanding as proposed by other researchers. To consider this concern, we follow the procedure used in previous studies and display one calculation example (when initially selecting 500 JPY), along with two calculation exercises (when initially selecting 1000 JPY and 0 JPY) (See the Figure Appendices C and D). By so doing, we help the participants understand their assigned schemes.

Furthermore, we set up the survey screen to automatically calculate and display the "initially selected amount," "reward to self," and "donated amount to the charity" after the participants choose their initial amount (See the Figure Appendix E). Then, if they agree with the calculated results, they have to click a button to confirm their selection. These features are useful in preventing confusion or misunderstanding and isolation effect, which have been pointed out by previous studies.

\subsection{Descriptive statistics}

Table 2 reports the means and standard deviations of participants' gender, marital status, number of children, years of education, household income, and place of residence for each group to check the random allocation of participants between the five groups. We confirm that there is no statistically significant difference in the means of all the variables in the table between the groups. ${ }^{12}$

\subsection{Empirical strategy}

In the next sections, after presenting descriptive analysis, we estimate the effects of rebates and matchings, using the ordinary least squares regression and the following model specification:

\footnotetext{
12 When looking at household income, the mean of the control is 4.6 million JPY, while the means of the $50 \%$ rebate and 1:1 matching are in the range of 4.9 million JPY, the latter being approximately 300,000 JPY higher; however, the difference is not statistically significant.
} 


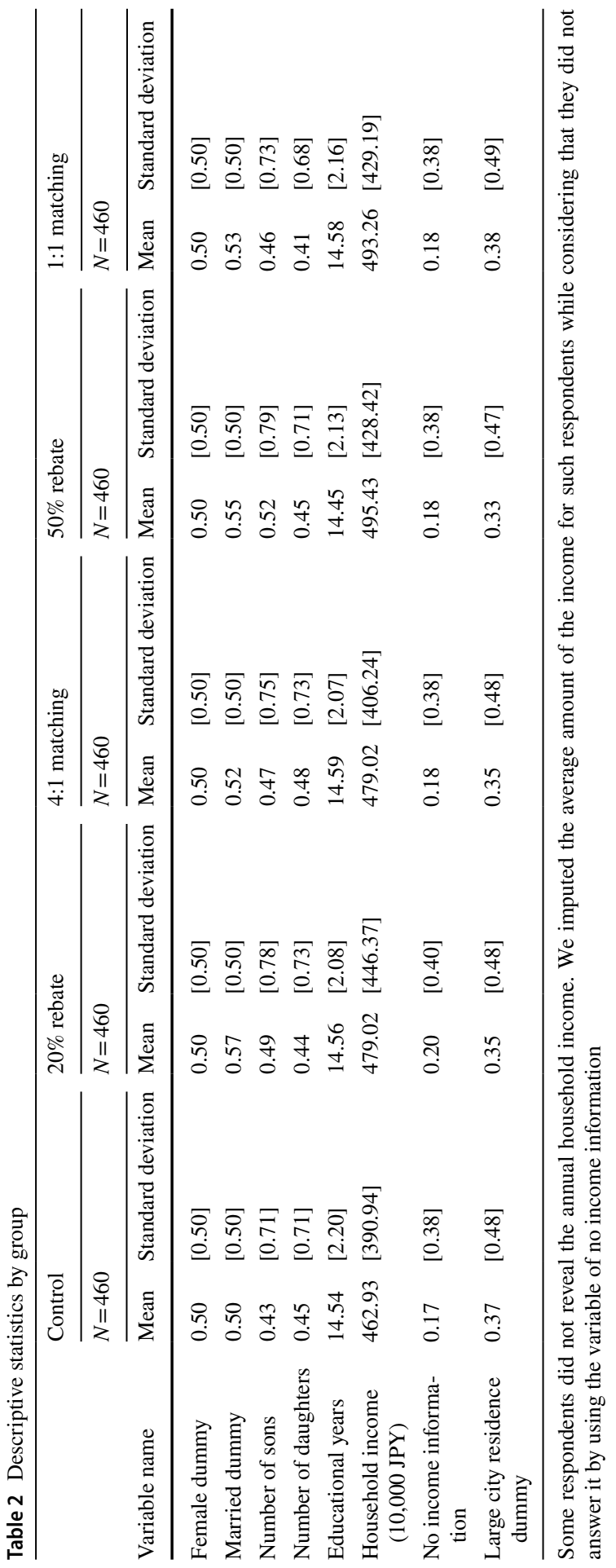




$$
y_{i}=\alpha+\gamma_{1} 20 \% \text { Rebate }_{i}+\gamma_{2} 4{\text { to } 1 \text { Match }_{i}+\gamma_{3} 50 \% \text { Rebate }_{i}+\gamma_{4} 1 \text { to } \text { Match }_{i}+z_{i}^{\prime} \delta+u_{i}} .
$$

The dependent variable $y_{i}$ refers to participant $i$ 's actual donation expenditure. $\alpha$ is a constant term, and $\gamma_{1}-\gamma_{4}$ are the treatment effects of $20 \%$ rebate, 4:1 matching, $50 \%$ rebate, and 1:1 matching. $z_{i}$ is a vector of participant $i$ 's socioeconomic attributes described above and behavioral economics characteristics, including social preference, time preference, and risk preference; $u_{i}$ is a random error term.

\section{Basic analysis}

Table 3 compiles donation amounts by group, in line with the table presented in Eckel and Grossman (2003). Row (1) shows the initially selected amount in response to the question "If you win and earn 1000 JPY, how much of the 1000 JPY are you willing to pass on to the worldwide afforestation activities? Please answer in increments of 100 JPY." Row (2) shows the actual donation expenditure, which is the donation amount after refund in rebate. Row (2) is blank in the control and matching, showing that there is no change from the amount in row (1).

In row (3), by respectively comparing the control and four treatment groups, we find the following. First, the rebate treatments decrease the actual donation expenditure relative to the control. This tendency is strongly observed in particular for the $50 \%$ rebate treatment, where the average donation expenditure is approximately 126 JPY lower compared to the control $(p<0.01)$. Assume that an individual who selects $500 \mathrm{JPY}$ in the control is actually assigned a 50\% rebate. If they wish to keep the same donation expenditure as in a situation where they are assigned to the control, they need to select 1000 JPY. However, in reality, although the initially selected amount indeed increases, the extent of that increase is not large, and the actual donation expenditure after refund becomes lower than in the control. The results do not show that rebate promotes donation behavior.

Second, the matching treatments increase the actual donation expenditure relative to the control. This tendency is strongly observed in particular in the 1:1 matching treatment, where the average donation expenditure is approximately $56 \mathrm{JPY}$ higher compared to the control $(p<0.01)$. Assume that the same individual who selects $500 \mathrm{JPY}$ in the control is actually assigned to a $1: 1$ matching treatment. If they wish to have the similar amount donated to a charity as in a situation where they are assigned to the control, they only need to select 200 JPY or 300 JPY. However, in reality, their initially selected amount changes toward an increase, not a decrease. Specifically, those who select 500 JPY in the control actually select higher amounts, $600 \mathrm{JPY}, 700 \mathrm{JPY}$, or more, in the matching treatment. This result suggests that matching promotes donation behavior, encouraging higher donation expenditure.

Row (4) confirms the above results from a different perspective. If the rebate and matching treatments have the same impact on donation behavior, then no difference should be observed when comparing the average actual donation expenditures between a $20 \%$ rebate and $4: 1$ matching, and between a 50\% rebate and 1:1 matching treatment, respectively. However, we find that the average donation expenditure for the 4:1 


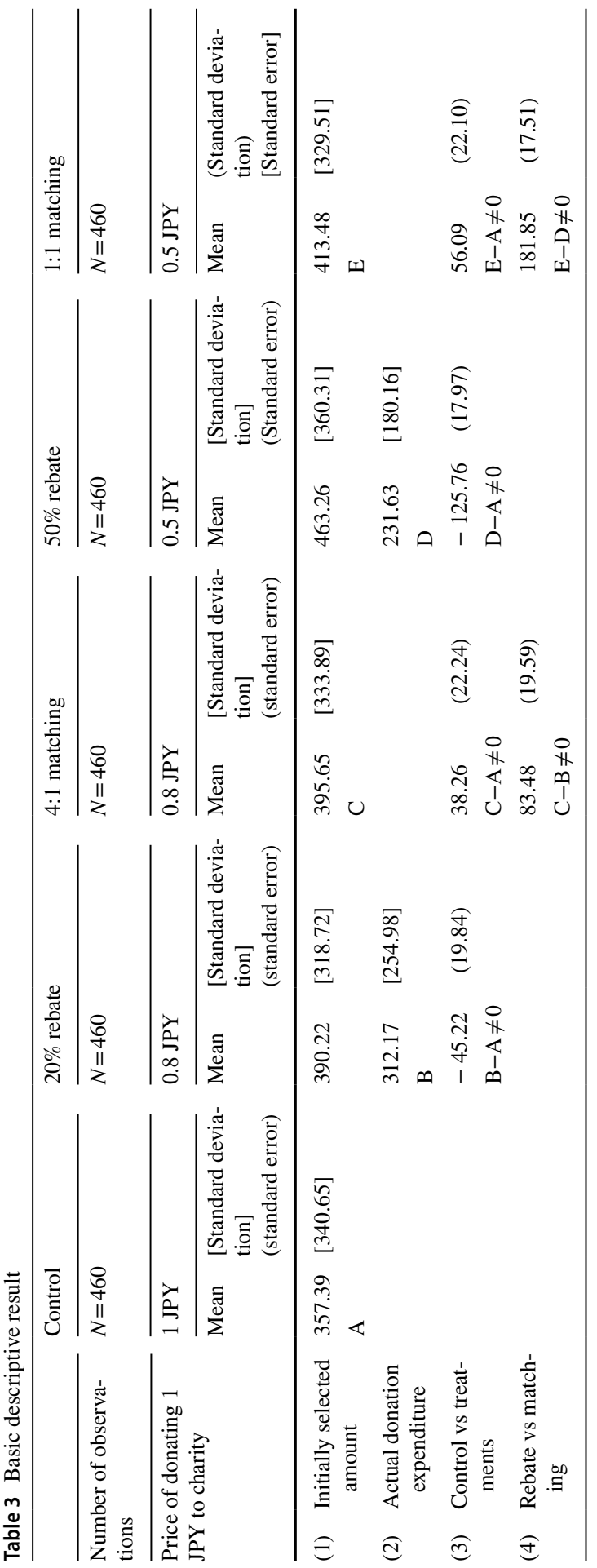


Table 4 Basic regression result

\begin{tabular}{|c|c|c|c|c|c|}
\hline \multirow[t]{2}{*}{ Dependent variable } & (1) & (2) & (3) & (4) & $(5)$ \\
\hline & \multicolumn{5}{|c|}{ Actual donation expenditure } \\
\hline \multirow{2}{*}{$\begin{array}{l}\text { Endowment } \\
\text { Estimation method }\end{array}$} & \multicolumn{5}{|l|}{$1000 \mathrm{JPY}$} \\
\hline & \multicolumn{5}{|l|}{ OLS } \\
\hline $20 \%$ rebate & $\begin{array}{l}-45.217 * * \\
(19.319)\end{array}$ & $\begin{array}{l}-47.491 * * \\
(17.827)\end{array}$ & $\begin{array}{l}-40.752^{* * *} \\
(14.269)\end{array}$ & Basement & - \\
\hline 4:1 matching & $\begin{array}{l}38.261 \\
(23.892)\end{array}$ & $\begin{array}{l}35.320 \\
(23.871)\end{array}$ & $\begin{array}{l}39.030^{*} \\
(20.622)\end{array}$ & $\begin{array}{l}81.958 * * * \\
(21.320)\end{array}$ & - \\
\hline $50 \%$ rebate & $\begin{array}{l}-125.761 * * * \\
(19.086)\end{array}$ & $\begin{array}{l}-128.272 * * * \\
(18.130)\end{array}$ & $\begin{array}{l}-121.341 * * * \\
(14.577)\end{array}$ & - & Basement \\
\hline 1:1 matching & $\begin{array}{l}56.087 * * * \\
(17.744)\end{array}$ & $\begin{array}{l}55.310 * * * \\
(17.157)\end{array}$ & $\begin{array}{l}50.863 * * * \\
(14.880)\end{array}$ & - & $\begin{array}{l}172.774 * * * \\
(13.233)\end{array}$ \\
\hline Socioeconomic attributes & No & Yes & Yes & Yes & Yes \\
\hline $\begin{array}{l}\text { Behavioral economic attrib- } \\
\text { utes }\end{array}$ & No & No & Yes & Yes & Yes \\
\hline Number of observations & 2300 & 2300 & 2300 & 920 & 920 \\
\hline
\end{tabular}

Cluster robust standard errors at prefecture level in parentheses

$* * * p<0.01, * * p<0.05, * p<0.1$

In columns $1-3$, we use the sample of all the groups. In column 4 , we use the sample of $20 \%$ rebate and 4:1 matching treatment groups, and in column 5, we use the sample of 50\% rebate and 1:1 matching treatment groups.

matching is approximately 83 JPY higher than for the $20 \%$ rebate $(p<0.01)$, and that the 1:1 matching is approximately 182 JPY higher than for the $50 \%$ rebate $(p<0.01)$.

Table 4 shows the OLS estimated effects of rebate and matching on actual donation expenditure, and Fig. 3 also presents the mean estimate and $95 \%$ confidence interval of the donation expenditure for each group. We find that the estimation results are consistent with the descriptive test results, after controlling for socioeconomic attributes and behavioral economics characteristics. The direct difference between $20 \%$ rebate and 4:1 matching is estimated at approximately 82 JPY $(p<0.01)$, while that between $50 \%$ rebate and 1:1 matching is estimated at approximately 173 JPY $(p<0.01)$. When we use Type 1 Tobit model and conduct estimation to consider the bias due to the left censoring of $0 \mathrm{JPY}$, we find the robust difference between the rebate and matching.

In summary, we find through an experiment conducted on a Japanese sample of 2300 respondents that matching is superior to rebate in encouraging higher donation expenditures. This superiority is strongly and robustly observed in particular in the comparison of the $50 \%$ rebate and 1:1 matching treatments. ${ }^{13}$ Our results are essentially consistent with the tendencies found in a series of experimental studies conducted by Eckel and Grossman.

\footnotetext{
13 Table Appendix A shows the effect of each treatment on the binary choice of whether to donate. Although all the treatments increase the donation probability, the $20 \%$ rebate's effect is larger than that of 4:1 matching. Considering the results of Sect. 4, $20 \%$ rebate could be less effective than 4:1 matching in increasing the average donation expenditure (intensive margin), but more effective in increasing
} 
Fig. 3 Actual donation expenditure by group. Notes: The unit is Japanese yen. The vertical line represents a $95 \%$ confidence interval

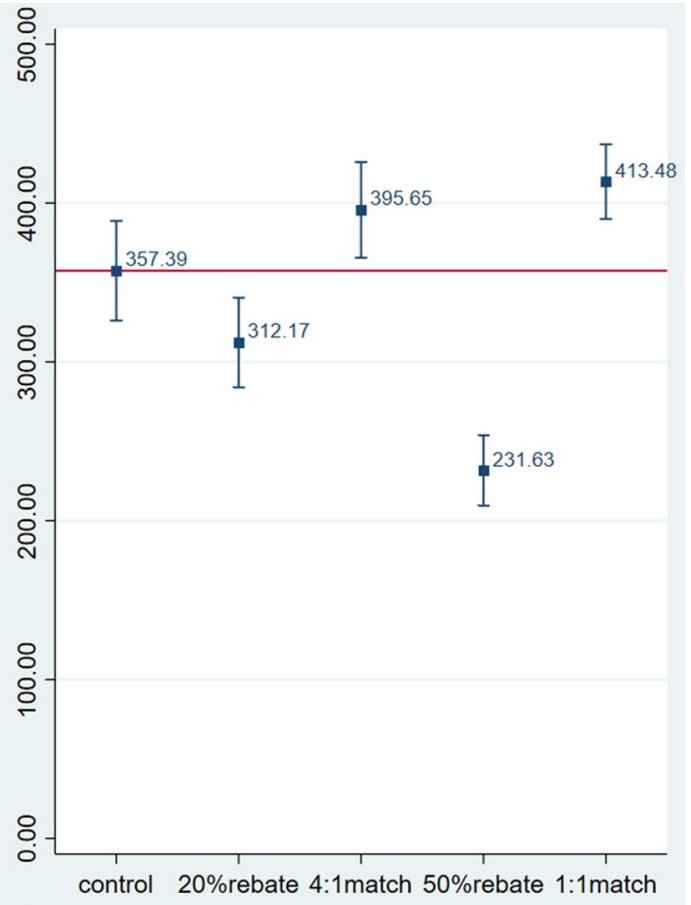

\section{Further analysis}

\subsection{Confusion or misunderstanding}

This section examines the relationship between the understanding of how rebate or matching treatments work and their treatment effects. As explained in the Procedures section, this economic experiment provides participants with one calculation example and two calculation exercises to support their understanding of the treatment assigned to them. Specifically, we show the formulae and the amounts of "reward to self" and "donated amount to the charity" in the case when they initially select $500 \mathrm{JPY}$ in their assigned treatment group. We then provide two calculation exercises asking what these two amounts would be, when initially selecting $1000 \mathrm{JPY}$ and 0 JPY. However, we do not provide feedback as to whether their answers are correct or incorrect. Thus, there might be some participants who join the experiment without having their misunderstanding of the calculation process corrected. If the effects in "Basic analysis" are generated mainly because of the participants with misunderstandings, the superiority of matching in this study would depend on their confusion or misunderstanding, unlike in Eckel and Grossman's case.

Footnote 13 (continued)

the donation probability (extensive margin). There is no statistically significant difference between $50 \%$ rebate and 1:1 matching in increasing the donation probability. 
Table 5 shows the proportion of correct answers to the calculation exercises in each treatment group. The proportions of those who correctly answer both questions are not high throughout the results, being approximately 50\%. Matching treatment results appear slightly easier to calculate out. The proportion of correct answers for the $4: 1$ matching is about $9 \%$ higher than for the $20 \%$ rebate $(p<0.01)$, while that for the $1: 1$ matching is about $6 \%$ higher than for the $50 \%$ rebate $(p<0.10)$. However, that being said, more than half the participants incorrectly answered either of the questions for the $1: 1$ matching.

First, we examine whether the superiority of matching over rebate is observed even after directly controlling for correctly answering both questions. Since we do not provide the exercises to the participants in the control, we assume that they are all sufficiently aware of the relationship between the "initially selected amount," "reward to self," and "donated amount to the charity." As shown in Table 1, the relationship in the control is quite simpler than in the four treatment groups, and therefore this assumption is plausible. Table 6 shows that correctly answering both questions increases the actual donation expenditure, on average. However, after controlling for it, we still find a similar tendency, where matching encourages larger donations than rebate.

Second, by dividing the participants into one group that correctly answers both questions and another group that does not, we estimate the effect of the matching scheme while taking the rebate scheme as a base. Table 7 shows that, regardless of whether the participants answer the two problems correctly or not, matching increases the actual donation expenditure more than rebate. When comparing $20 \%$ rebate and 4:1 matching, the average donation expenditure under matching is around $80 \mathrm{JPY}$ higher than under rebate in both the correct-answer and the incorrect-answer samples (at least $p<0.05$ ). When comparing 50\% rebate and 1:1 matching, the superiority of matching is observed in the correct-answer sample, with a large difference of around $200 \mathrm{JPY}(p<0.01)$. Also in the incorrect-answer sample, the average donation expenditure under matching is around 150 JPY higher than that under rebate $(p<0.01)$.

The findings reject the concern that the results in "Basic analysis" may be explained conclusively by participants' confusion or misunderstanding. However, we certainly cannot ignore the behavior of the incorrect-answer sample, in particular when using a rebate or matching as a method to encourage donations in the real world. Nearly half of the study participants answered questions incorrectly, despite being provided with formulae and one calculation example beforehand. The proportion of individuals who do not correctly understand the schemes will become much higher in reality. Thus, the comparative results of the two schemes in the real world will depend on the behavior of people who misunderstand the schemes. Since this study finds the relative effectiveness of matching also in the incorrect-answer sample, it implies that even if rebate and matching are provided to a more general population, matching can still promote donation behavior more than rebate.

Then, who correctly answers the calculation exercises, and who does not? Our simple correlation analysis shows that those with higher education, higher income, and those living in urban areas are more likely to answer both questions 


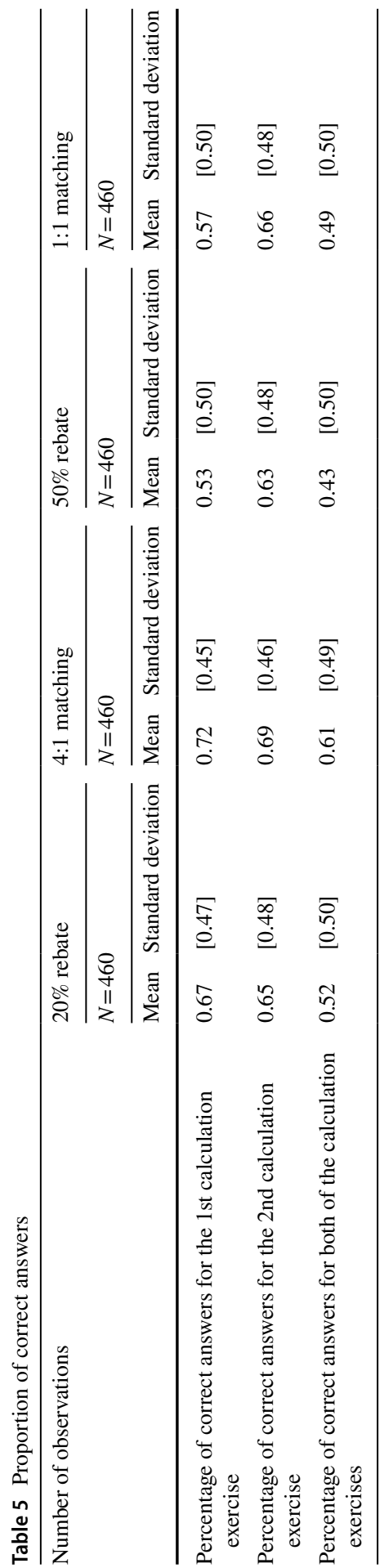


Table 6 Further analysis: confusion or misunderstanding (a)

\begin{tabular}{|c|c|c|c|c|c|}
\hline \multirow[t]{2}{*}{ Dependent variable } & (1) & $(2)$ & (3) & (4) & (5) \\
\hline & \multicolumn{5}{|c|}{ Actual donation expenditure } \\
\hline Endowment & \multicolumn{5}{|l|}{$1000 \mathrm{JPY}$} \\
\hline Estimation method & \multicolumn{5}{|l|}{ OLS } \\
\hline $20 \%$ rebate & $\begin{array}{l}-26.914 \\
(19.860)\end{array}$ & $\begin{array}{l}-30.413 \\
(18.900)\end{array}$ & $\begin{array}{l}-26.392 \\
(15.745)\end{array}$ & Basement & - \\
\hline 4:1 matching & $\begin{array}{l}53.251 * * \\
(23.393)\end{array}$ & $\begin{array}{l}49.424 * * \\
(23.578)\end{array}$ & $\begin{array}{l}50.844 * * \\
(20.381)\end{array}$ & $\begin{array}{l}80.979 * * * \\
(21.593)\end{array}$ & - \\
\hline $50 \%$ rebate & $\begin{array}{l}-103.896^{* * *} \\
(20.498)\end{array}$ & $\begin{array}{l}-107.884 * * * \\
(19.625)\end{array}$ & $\begin{array}{l}-104.122 * * * \\
(16.484)\end{array}$ & - & Basement \\
\hline 1:1 matching & $\begin{array}{l}75.550 * * * \\
(17.959)\end{array}$ & $\begin{array}{l}73.658 * * * \\
(17.707)\end{array}$ & $\begin{array}{l}66.169 * * * \\
(16.216)\end{array}$ & - & $\begin{array}{l}169.526 * * * \\
(13.396)\end{array}$ \\
\hline Correct answer & $\begin{array}{l}38.097 * * * \\
(13.304)\end{array}$ & $\begin{array}{l}35.835 * * * \\
(11.998)\end{array}$ & $\begin{array}{l}30.029 * * \\
(11.245)\end{array}$ & $\begin{array}{l}11.707 \\
(17.157)\end{array}$ & $\begin{array}{l}49.365 * * * \\
(12.085)\end{array}$ \\
\hline Socioeconomic attributes & No & Yes & Yes & Yes & Yes \\
\hline $\begin{array}{l}\text { Behavioral economic attrib- } \\
\text { utes }\end{array}$ & No & No & Yes & Yes & Yes \\
\hline Number of observations & 2300 & 2300 & 2300 & 920 & 920 \\
\hline
\end{tabular}

Cluster robust standard errors at prefecture level in parentheses

$* * * p<0.01, * * p<0.05, * p<0.1$

In columns $1-3$, we use the sample of all the groups. In column 4 , we use the sample of $20 \%$ rebate and $4: 1$ matching treatment groups, and in column 5, we use the sample of 50\% rebate and 1:1 matching treatment groups.

correctly. In other words, the mechanism behind the superiority of matching over rebate may vary across these segments.

\subsection{Budget constraint lines}

The experimental design of this study is based on Eckel and Grossman's studies. As Blumenthal et al. (2012) point out, the price of donation is equivalent between rebate and matching, while their budget constraint lines are not completely the same (See the Figure Appendix A). Subjects who would spend 1000 JPY on a donation in the control can spend only $500 \mathrm{JPY}$ in a $50 \%$ rebate. Even if they select the same initial amount of $1000 \mathrm{JPY}, 50 \%$ of that amount is refunded to them. If they are assigned to a 1:1 matching, they can maintain the same 1000 JPY donation expenditure. Similarly, the $50 \%$ rebate allows subjects to select an amount donated to charity of between 0 and $1000 \mathrm{JPY}$ only, while the 1:1 matching allows them to select the amount between 0 and 2000 JPY.

We will confirm that the budget constraint lines' difference does not critically determine our experimental results in the following two ways. The first is to increase participants' endowment so that their decision to donate is not affected by 


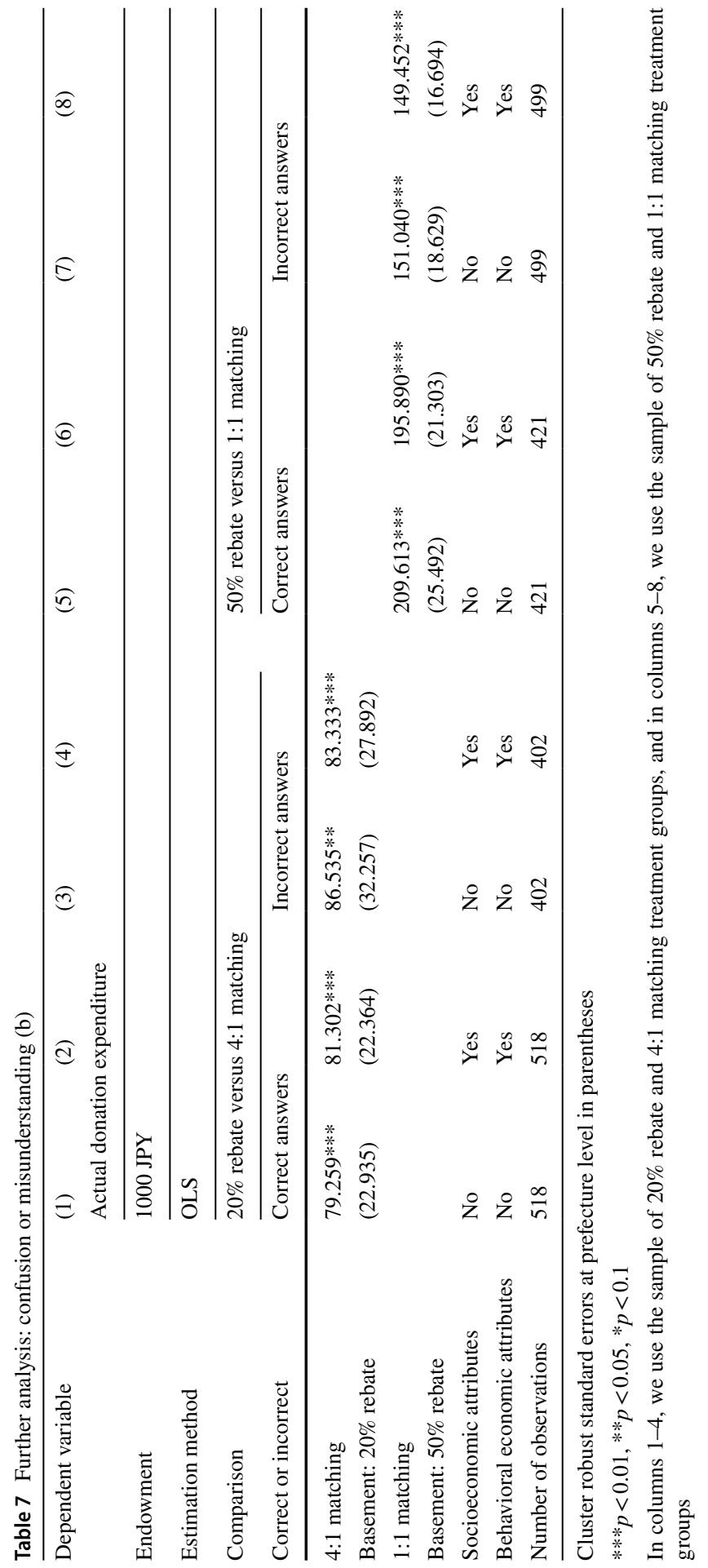


the truncation. Specifically, we increase their endowment amount from 1000 JPY to 5000 JPY and 10,000 JPY, using hypothetical experimental questions. In this study, after the incentivized economic experiment, we set questions to ascertain how much of an endowment the participants are willing to pass on to the same recipient, when the endowment is changed to 5000 JPY and 10,000 JPY under the same treatment. In general, it is known that the ratio of donation expenditure to income declines as income rises (James III \& Sharpe, 2007). Therefore, in the above situations, there should be fewer cases in which some people in the rebate treatments who wish to maintain or increase their own donation expenditure are unable to do so due to their budget constraint.

Table 8 shows that even after increasing the endowment, we still find that rebate has the effect of decreasing the actual donation expenditure and matching has the effect of increasing it. In particular, the average donation expenditure in the $50 \%$ rebate treatment is considerably lower than in the control, despite the high endowments allowing the participants to initially select higher amounts. Consequently, the superiority of the 1:1 matching over the $50 \%$ rebate is robustly found in both 5000 JPY and 10,000 JPY endowments $(p<0.01)$. We also find this superiority in the comparison of the $20 \%$ rebate and 4:1 matching treatments: however, the statistical significance of their difference is relatively weak $(p<0.10)$.

The second is to limit the analysis sample to the participants who make their donation decision, to the extent that it is not influenced by the truncation. We use the estimated parameters for the control group, ${ }^{14}$ and calculate out the predicted values for the four treatment groups for "how much they would spend on a donation if they were assigned to the control." (1) We restrict the participants in $20 \%$ rebate and $50 \%$ rebate to those with a predicted value of $800 \mathrm{JPY}$ or less and to those with a predicted value of 500 JPY or less, respectively. In other words, we use only those who do not face a situation, where the budget constraint' truncation causes a decrease in their donation expenditure in the rebate treatments. (2) We limit the participants in the control group to those with the actual donation expenditure of $800 \mathrm{JPY}$ or less and to those with that of 500 JPY or less. (3) We further impose both the restrictions on the participants in the 4:1 matching and 1:1 matching treatments. That is, we use only those in the matching treatments who have the same maximum predicted value and actual donation expenditure as in the rebate treatments.

Here, it should be noted that the second restriction to the donation expenditure in the matching places this scheme's position at a relative disadvantage. For example, in the case of the 1:1 matching, this restriction excludes those who are predicted to spend a donation amount of less than 500 JPY in the control group and actually donate 500 JPY or more in the 1:1 matching treatment. Since the participants with positive and larger individual treatment effects of matching are excluded from the analysis, this will diminish its average positive treatment effect.

\footnotetext{
14 More precisely, we use the control group's sample and regress the donation expenditure amount on the following socioeconomic variables: gender, marital status, number of children, years of educations, household income, and place of residence. We then use the estimated parameters of these variables and predict the dependent variable's value for the four treatment groups.
} 


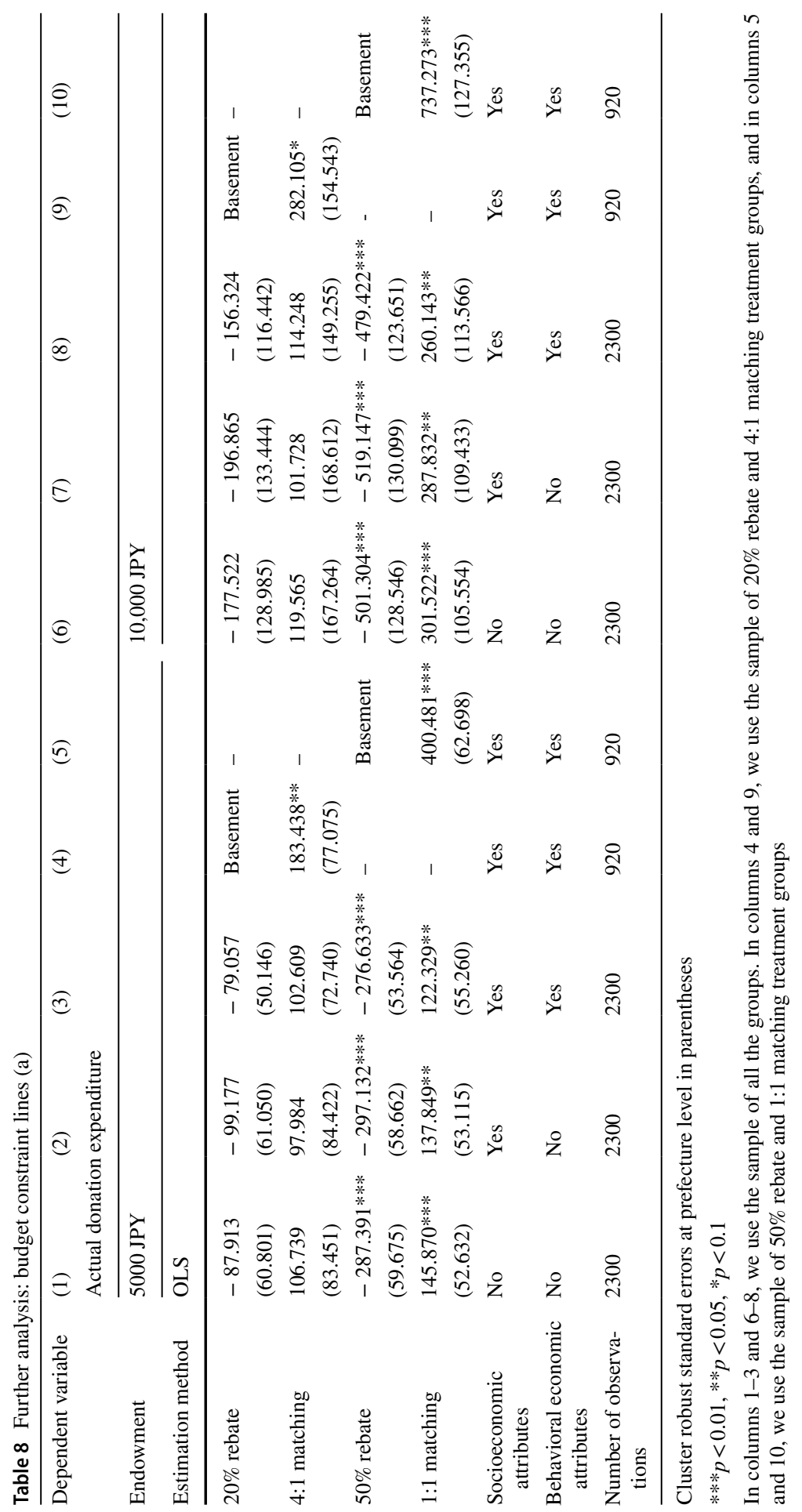


We find from Table 9 that 1:1 matching remains superior to $50 \%$ rebate under such the disadvantageous condition, although the relative effectiveness of $4: 1$ matching disappears. In columns 3 and 4, the restriction eliminates the difference between the $4: 1$ matching and the $20 \%$ rebate, and this may be evidence supporting that $4: 1$ matching's superiority in the previous sections is accidentally generated by the difference in budget constraint lines. ${ }^{15}$ In contrast, columns 7 and 8 show that although the $50 \%$ rebate's effect of decreasing actual donation expenditure has disappeared, the 1:1 matching's increasing effect is persistent, despite limiting the analysis sample in the 1:1 matching to those not only with a predicted value of $500 \mathrm{JPY}$ or less but also with the actual donation expenditure of $500 \mathrm{JPY}$ or less. Its effect size is around $50 \mathrm{JPY}$ and statistically significant $(p<0.01)$. This result strongly supports the relative effectiveness of the $1: 1$ matching treatment. In addition, we posit that the superiority of 1:1 matching over $50 \%$ is not conclusively influenced by the difference in their budget constraint lines.

\section{Discussion, limitations and conclusions}

This study uses a Japanese nationwide sample and experimentally compares rebate and matching, both of which are subsidy schemes intended to lower the price of donation and encourage donation behavior in individuals. The experimental result shows that even if the donation price is equal between matching and rebate treatments, matching, which lowers the price by adding a contribution from a third party, increases people's actual donation expenditure more than rebate, which lowers the price through refunds. The descriptive result shows that the actual donation expenditure drops by around $126 \mathrm{JPY}$ when assigned to the $50 \%$ rebate as compared to the control, while it increases by around 56 JPY when assigned to the 1:1 matching (which has essentially the same donation price as $50 \%$ rebate). This tendency is consistent with the results observed in a series of experimental studies by Eckel and Grossman. We empirically confirm that, in particular, the superiority of 1:1 matching on $50 \%$ rebate is not critically influenced by people's confusion or misunderstanding, or the difference in budget constraint lines between rebate and matching. In other words, as Eckel and Grossman say, the framings' difference would partly generate the 1:1 matching's superiority among the Japanese people.

Our findings suggest that implementing the matching scheme in Japan has a greater potential to increase Japanese people's donations. The Japanese government has so far focused on improving the rebate scheme, while there remains considerable scope for the implementation of matching. According to the Economic Planning Agency (2008), the matching scheme in Japan has been narrowly understood as "a scheme for corporations to match the donations of their employees to charities," and frequently adopted for promoting their employees' social contribution activities.

\footnotetext{
${ }^{15}$ However, we also cannot deny the possibility that the additional and disadvantageous restriction to 4:1 matching decreases its treatment effect more than necessary and hides 4:1 matching's superiority. Our sample restriction will work when matching's superiority is still observed.
} 


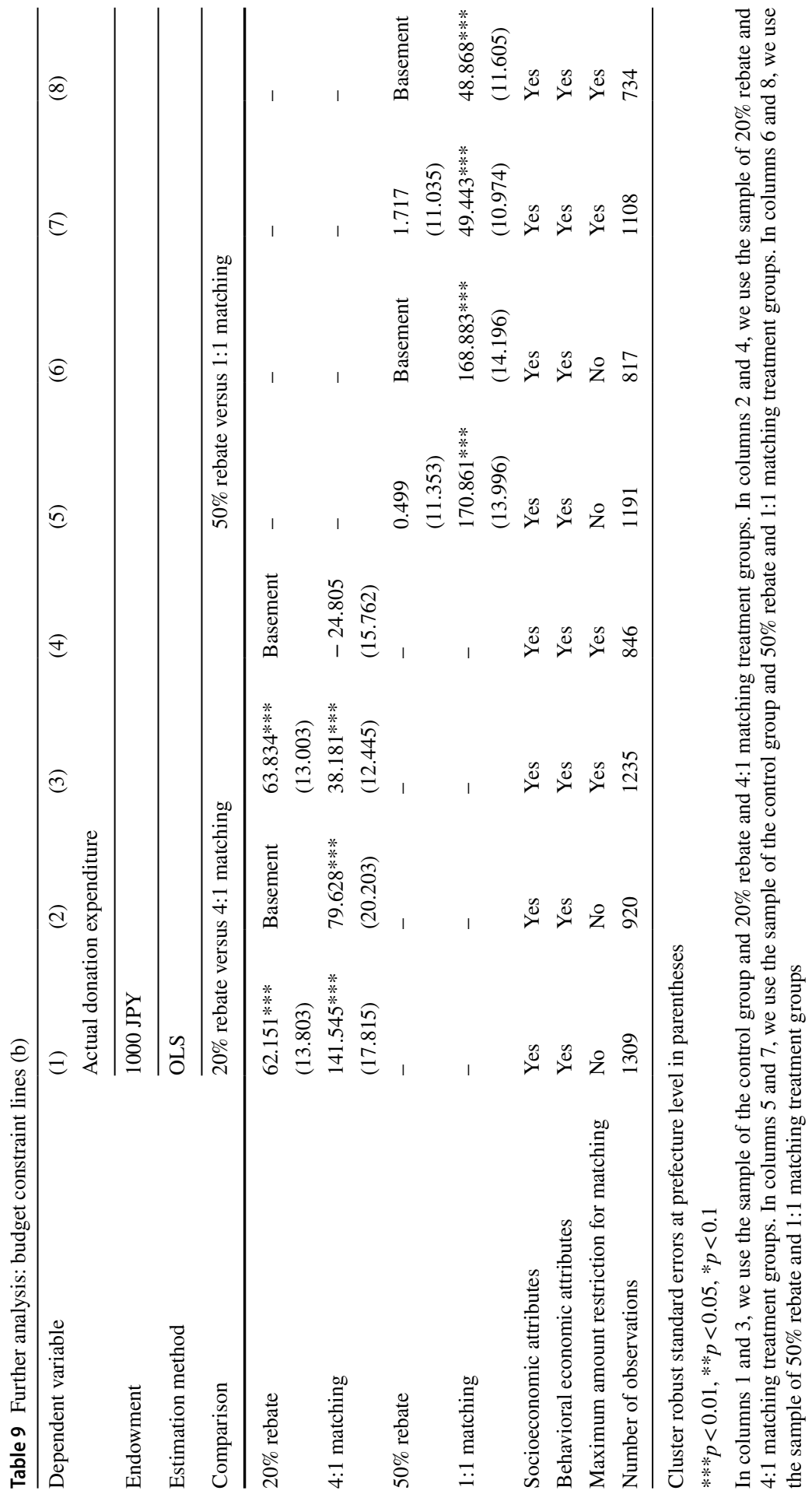


However, there are small number of corporations that have introduced the matching scheme. For example, in 2019 , about $78 \%$ of the corporations that responded to a survey did not implement the scheme (Toyo Keizai Inc., 2020). It is necessary to consider measures to increase the number of corporations that adopt the matching scheme, as well as to expand this scheme outside of corporations.

It should be noted that matching is not a panacea either. Matching induces larger donations than rebate, but it does not have a positive effect on all individuals' donations. Under the matching scheme, some people might wish to increase their outof-pocket donation expenditure, but others might wish to reduce it. The latter group may think that even if they reduce their own out-of-pocket donation expenditure, the donation amount received by a charity through matching is sufficient. This phenomenon is known as "crowding out" in economics (Huck \& Rasul, 2011; Karlan \& List, 2007). Recent economic studies have started to explore options to prevent crowding out and improve the efficiency of the matching scheme, specifically proposing that the matched amount is donated to other charitable projects, setting some thresholds, etc. (Adena \& Huck, 2017, 2019; Charness \& Holder, 2019; Huck et al., 2015). It is also necessary to consider these options before implementing the matching scheme in the Japanese society. In other words, such options could further increase the superiority of matching over rebate.

We now discuss the limitations of this study. The participants in our economic experiment receive their endowment as a windfall, as in Eckel and Grossman's studies. Their behavior may not completely be consistent with the behavior of people in the real world, many of who make donations from their salaries. In addition, participants in some previous laboratory experiments could freely choose an organization as a donation recipient from multiple NPOs, while in this study, we specify the organization in advance: one engaged in afforestation activities. In other words, our study participants may include a large sample of people who had no previous intention to donate to the organization. Our experimental results may be affected by the phenomena where such the people are encouraged to make a larger donation by the matching scheme. Future research should confirm the generalizability of this study's results before promoting the implementation of matching in the Japanese society. Nevertheless, we believe that this study has sufficient academic and policy significance in that it is the first to experimentally demonstrate the superiority of matching over rebate in Japan. 


\section{Appendix}

\section{See Figure Appendix A, B, C, D and E and Table Appendix A}

(a) Xaxis is "Actual donation expenditure"

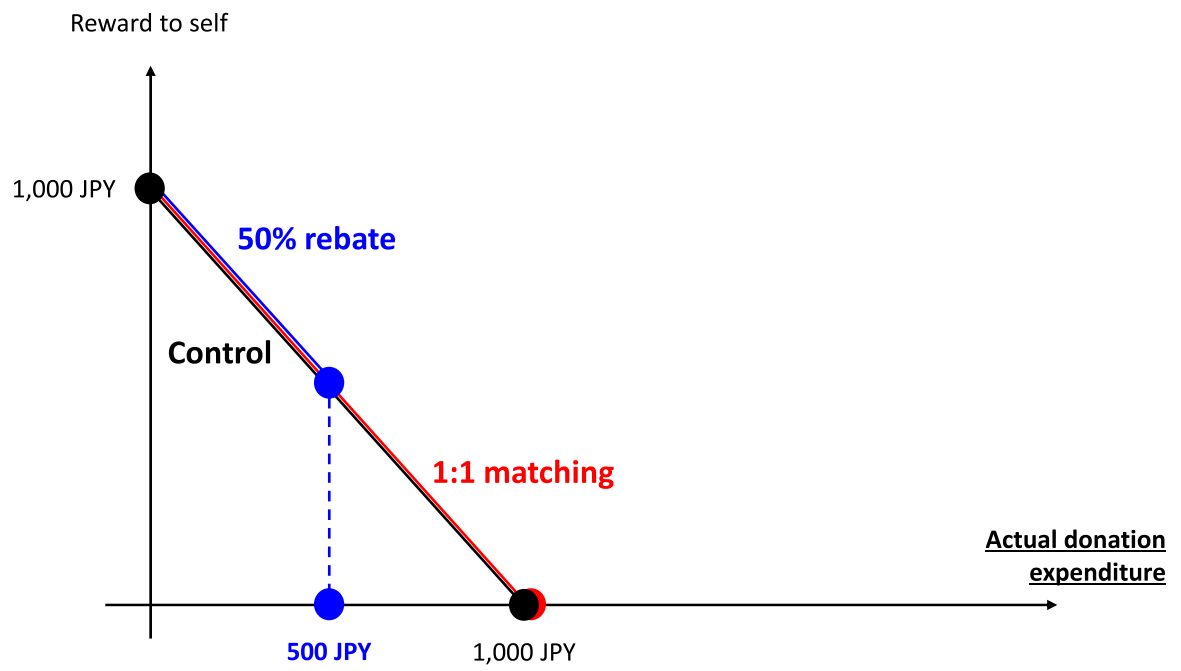

(b) X axis is "Donated amount to the charity"

Reward to self

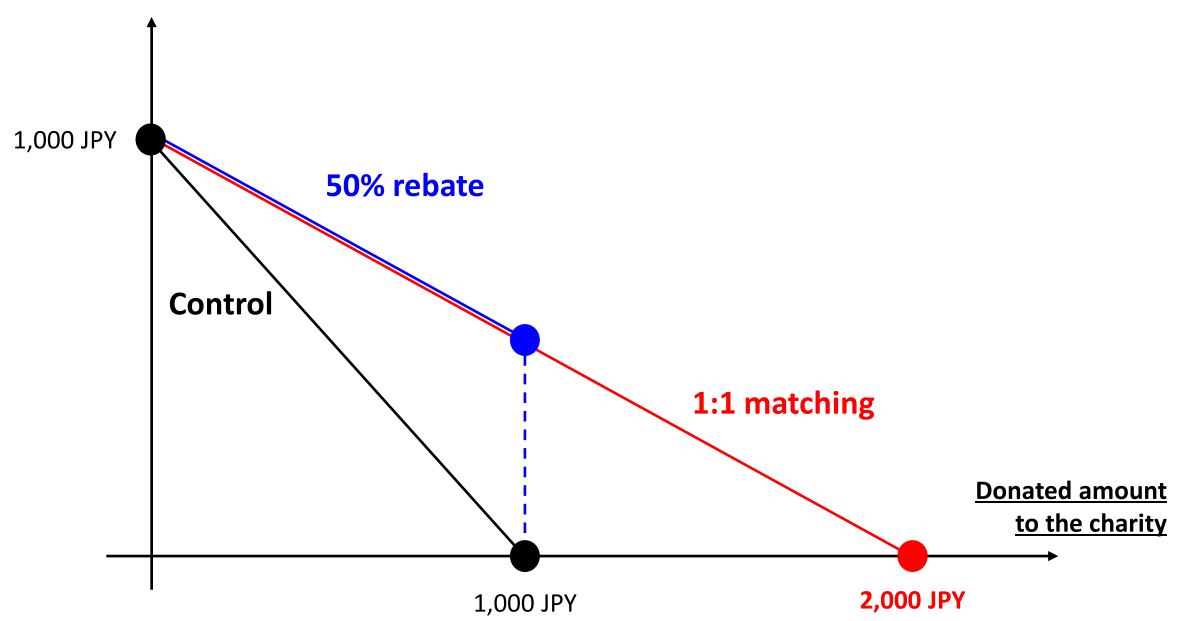

Fig. A Budget constraint lines (the case of control, 50\% rebate, and 1:1 matching) 
In a drawing (one in ten), you will win and earn reward points worth 1,000 JPY. Winners will be notified by email at a later date.

You can pass a part or all of the earned 1,000 JPY to a social contribution project.

From the next page, the experimenter will introduce to you the content of the project.

Assuming you could earn 1,000 JPY, please answer how much of the 1,000 JPY you will pass on to the project.

If you win and earn 1,000 JPY, your donation decision will be carried out as you answer.

$\square$ After winning, you cannot change your answer. So, please think carefully before answering.

$\square$ If you do not win, you will not earn 1,000 JPY, but your donation decision will not be carried out either.

Fig. $\mathbf{B}$ The introductory page to the experiment

For example, if you initially select $\mathbf{5 0 0}$ JPY under this scheme, your reward amount will be $\mathbf{5 0 0}$ JPY and the amount donated to the afforestation activities will be 1,000 JPY.

Initially selected amount $=500 \mathrm{JPY}$

Reward to self $=1,000 \mathrm{JPY}$ - Initially selected amount (500 JPY) $=\mathbf{5 0 0} \mathrm{JPY}$

Donated amount to the charity = Initially selected amount (500 JPY) $\times 2=1,000 \mathrm{JPY}$

Fig. C The screen for the calculation example (the case of 1:1 matching)

Calculation exercise 1 . Please select the correct combination of the amounts that enter $A$ and $B$ in the text.

If you initially select $\mathbf{1 , 0 0 0}$ JPY under this scheme, your reward amount will be $\mathbf{A}$ and the amount donated to the afforestation activities will be $\mathbf{B}$.

1) A: 0 JPY B: $1,000 \mathrm{JPY}$

2) A: 0 JPY B: $2,000 \mathrm{JPY}$

3) $\mathrm{A}: 1,000 \mathrm{JPY} \quad \mathrm{B}: 1,000 \mathrm{JPY}$

Calculation exercise 2. Please select the correct combination of the amounts that enter $C$ and $D$ in the text.

If you initially select $\mathbf{0}$ JPY under this scheme, your reward amount will be $\mathbf{C}$ and the amount donated to the afforestation activities will be $\mathbf{D}$.

1) C: 1,000 JPY D: $0 \mathrm{JPY}$

2) C: 0 JPY D: $1,000 \mathrm{JPY}$

3) C: $1,000 \mathrm{JPY} \quad \mathrm{D}: 1,000 \mathrm{JPY}$

Fig. D The screen for the calculation exercises (the case of 1:1 matching). Notes: The numbers of correct answers are 2) and 1), respectively. The initially selected amounts and the numbers of correct answers are common between 1:1 matching and the other treatments (20\% rebate, $4: 1$ matching, and 50\% rebate) 


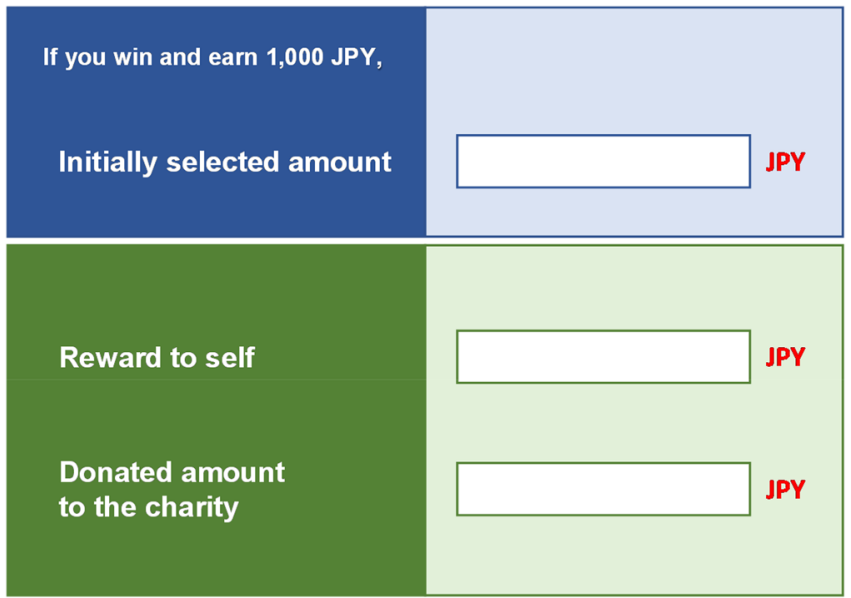

If you are satisfied with the above amounts, please click the "Next" button. If you want to change them, please select again the amount that you pass on to the charity.

Fig. $\mathbf{E}$ The screen for the donation decision

Table A Whether to donate (binary choice)

\begin{tabular}{|c|c|c|c|c|c|}
\hline \multirow[t]{2}{*}{ Dependent variable } & (1) & (2) & (3) & (4) & $(5)$ \\
\hline & \multicolumn{5}{|c|}{ Whether to donate (binary choice) } \\
\hline Endowment & \multicolumn{5}{|l|}{$1000 \mathrm{JPY}$} \\
\hline Estimation method & \multicolumn{5}{|c|}{ Linear probability model } \\
\hline $20 \%$ rebate & $\begin{array}{l}0.109 * * * \\
(0.025)\end{array}$ & $\begin{array}{l}0.107 * * * \\
(0.024)\end{array}$ & $\begin{array}{l}0.116 * * * \\
(0.021)\end{array}$ & Basement & - \\
\hline 4:1 matching & $\begin{array}{l}0.052 * * \\
(0.025)\end{array}$ & $\begin{array}{l}0.049 * \\
(0.025)\end{array}$ & $\begin{array}{l}0.053 * * \\
(0.020)\end{array}$ & $\begin{array}{l}-0.060^{* *} \\
(0.024)\end{array}$ & - \\
\hline $50 \%$ rebate & $\begin{array}{l}0.083 * * * \\
(0.024)\end{array}$ & $\begin{array}{l}0.080 * * * \\
(0.023)\end{array}$ & $\begin{array}{l}0.088 * * * \\
(0.019)\end{array}$ & - & Basement \\
\hline 1:1 matching & $\begin{array}{l}0.080 * * * \\
(0.025)\end{array}$ & $\begin{array}{l}0.080 * * * \\
(0.025)\end{array}$ & $\begin{array}{l}0.077 * * * \\
(0.023)\end{array}$ & - & $\begin{array}{l}-0.010 \\
(0.021)\end{array}$ \\
\hline Socioeconomic attributes & No & Yes & Yes & Yes & Yes \\
\hline Behavioral economic attributes & No & No & Yes & Yes & Yes \\
\hline Number of observations & 2300 & 2300 & 2300 & 920 & 920 \\
\hline
\end{tabular}

Cluster robust standard errors at prefecture level in parentheses

$* * * p<0.01, * * p<0.05, * p<0.1$

In columns $1-3$, we use the sample of all the groups. In column 4 , we use the sample of $20 \%$ rebate and 4:1 matching treatment groups, and in column 5, we use the sample of 50\% rebate and 1:1 matching treatment groups 
Acknowledgements We thank Nobuyuki Hanaki, Kazuhito Ogawa, and an anonymous referee for their insightful suggestions. We also thank Lata Gangadharan, Masao Ogaki, Charles Yuji Horioka, Shunichiro Sasaki, and participants at the International Workshop for Lab and Field Experiments (co-organized by Japanese Economic Association; Research Center for Behavioral Economics, Institute of Social and Economic Research at Osaka University; and Research Institute for Socionetwork Strategies at Kansai University) and the ABEF's 13th Annual Conference 2019 for discussions, comments, and encouragement. At the ABEF's conference, Shusaku Sasaki received Encouragement Award 2019 for poster presentation.

Funding This research was financially supported by the Japan Society for the Promotion of Science [JSPS Grant Numbers: 19K13722 (S., Sasaki) and 20H05632 (F., Ohtake)] and the Behavioral Economics Research Center at the Institute of Social and Economic Research of Osaka University.

\section{Declarations}

Conflict of interest We declare no conflicts of interest.

Open Access This article is licensed under a Creative Commons Attribution 4.0 International License, which permits use, sharing, adaptation, distribution and reproduction in any medium or format, as long as you give appropriate credit to the original author(s) and the source, provide a link to the Creative Commons licence, and indicate if changes were made. The images or other third party material in this article are included in the article's Creative Commons licence, unless indicated otherwise in a credit line to the material. If material is not included in the article's Creative Commons licence and your intended use is not permitted by statutory regulation or exceeds the permitted use, you will need to obtain permission directly from the copyright holder. To view a copy of this licence, visit http://creativecommons.org/licen ses/by/4.0/.

\section{References}

Adena, M., \& Huck, S. (2019). Personalized fundraising: A field experiment on threshold matching of donations. Available at SSRN 3480472.

Adena, M., \& Huck, S. (2017). Matching donations without crowding out? Some theoretical considerations, a field, and a lab experiment. Journal of Public Economics, 148, 32-42.

Andreoni, J. (1989). Giving with impure altruism: Applications to charity and Ricardian equivalence. Journal of Political Economy, 97(6), 1447-1458.

Andreoni, J. (1990). Impure altruism and donations to public goods: A theory of warm-glow giving. The Economic Journal, 100(401), 464-477.

Bekkers, R. (2015). When and why matches are more effective subsidies than rebates. Replication in Experimental Economics (pp. 183-211). Emerald Group Publishing Limited.

Bénabou, R., \& Tirole, J. (2006). Incentives and prosocial behavior. American Economic Review, 96(5), $1652-1678$.

Blumenthal, M., Kalambokidis, L., \& Turk, A. (2012). Subsidizing charitable contributions with a match instead of a rebate: What happens to donations and compliance? National Tax Journal, 65(1), 91.

Blumkin, T., Ruffle, B. J., \& Ganun, Y. (2012). Are income and consumption taxes ever really equivalent? Evidence from a real-effort experiment with real goods. European Economic Review, 56(6), $1200-1219$.

Cabinet Office (2019a), Cabinet Office NPO Website Overview of rebates (https://www.npo-homepage. go.jp/about/seidokaisei-keii/koujo-gaiyou) Accessed: April 21, 2019. (In Japanese)

Cabinet Office (2019b), Survey of Citizen Contributions to Society (https://www.npo-homepage.go. jp/toukei/shiminkouken-chousa/2019shiminkouken-chousa) Accessed: December 4, 2020. (In Japanese)

Charness, G., \& Holder, P. (2019). Charity in the laboratory: Matching, competition, and group identity. Management Science, 65(3), 1398-1407. 
Charness, G., Gneezy, U., \& Halladay, B. (2016). Experimental methods: Pay one or pay all. Journal of Economic Behavior \& Organization, 131, 141-150.

Davis, D. D. (2006). Rebate subsidies, matching subsidies and isolation effects. Judgment and Decision Making, 1(1), 13-22.

Davis, D. D., \& Millner, E. L. (2005). Rebates, matches, and consumer behavior. Southern Economic Journal, 72(2), 410-421.

Davis, D. D., Millner, E. L., \& Reily, R. J. (2005). Subsidy schemes and charitable contributions: A closer look. Experimental Economics, 8, 85-106.

Diederich, J., Eckel, C. C., Epperson, R., Goesch1, T., \& Grossman, P. J. (2020). Subsidizing Unit Donations: Matches, Rebates, and Discounts Compared (p. 0697). Discussion Paper Series / University of Heidelberg.

Eckel, C. C., \& Grossman, P. J. (2003). Rebate versus matching: Does how we subsidize charitable contributions matter? Journal of Public Economics, 87(3-4), 681-701.

Eckel, C. C., \& Grossman, P. J. (2006). Subsidizing charitable giving with rebates or matching: Further laboratory evidence. Southern Economic Journal, 72(4), 794-807.

Eckel, C. C., \& Grossman, P. J. (2008). Subsidizing charitable contributions: A natural field experiment comparing matching and rebate subsidies. Experimental Economics, 11(3), 234-252.

Eckel, C. C., \& Grossman, P. J. (2009). Encouraging giving: Subsidies in the field. SCSU Working Paper.

Eckel, C. C., \& Grossman, P. J. (2017). Comparing rebate and matching subsidies controlling for donors' awareness: Evidence from the field. Journal of Behavioral and Experimental Economics, 66, 88-95.

Economic Planning Agency (2008). White paper on national lifestyle: Volunteering to create fulfillment. Economic Planning Agency. (http://warp.da.ndl.go.jp/info:ndljp/pid/9990748/www5.cao.go.jp/seika tsu/whitepaper/wp-pl/wp-p100/hakusho-00-index.html) Accessed: April 22, 2019. (In Japanese).

Falk, A., Becker, A., Dohmen, T., Enke, B., Huffman, D., \& Sunde, U. (2018). Global evidence on economic preferences. The Quarterly Journal of Economics, 133(4), 1645-1692.

Giving Japan White Paper Research Society (2015). Giving Japan 2015. Japan Fundraising Association: Tokyo. (In Japanese).

Giving Japan White Paper Research Society (2017). Giving Japan 2017. Japan Fundraising Association: Tokyo. (In Japanese).

Huck, S., \& Rasul, I. (2011). Matched fundraising: Evidence from a natural field experiment. Journal of Public Economics, 95(5-6), 351-362.

Huck, S., Rasul, I., \& Shephard, A. (2015). Comparing charitable fundraising schemes: Evidence from a natural field experiment and a structural model. American Economic Journal: Economic Policy, $7(2), 326-369$.

Hungerman, D. M., \& Ottoni-Wilhelm, M. (2021). Impure impact giving: Theory and evidence. Journal of Political Economy, 129(5), 1553-1614.

James, R. N., III., \& Sharpe, D. L. (2007). The nature and causes of the U-shaped charitable giving profile. Nonprofit and Voluntary Sector Quarterly, 36(2), 218-238.

Karlan, D., \& List, J. A. (2007). Does price matter in charitable giving? Evidence from a large-scale natural field experiment. American Economic Review, 97(5), 1774-1793.

Kato, K. (2010). Expansion of taxation system for donations to NPOs. The National Diet Library's Reference, 715. (https://dl.ndl.go.jp/view/download/digidepo_3050285_po_071503.pdf?contentNo=1) Accessed: January 1, 2021. (In Japanese)

Kurokawa, H., Mori, T., \& Ohtake, F. (2020). A choice experiment on taxes: Are income and consumption taxes equivalent? Journal of Behavioral Economics and Finance, 13, 53-70.

Lukas, I., Grossman, P.J., \& Eckel, C.C. (2010). Preference or confusion: Understanding the differential impact of rebate and matching subsidies. Working Paper. Indiana University, Indianapolis, IN.

MyVoice.com Ltd. (2020). About reward points. (https://www.myvoice.co.jp/voice/about/point.html) Accessed: December 4, 2020. (In Japanese)

Salamon, L. M. (1994). The rise of the nonprofit sector. Foreign Affairs, 73(4), 109-122.

Sargeant, A., \& Shang, J. (2017). Fundraising Principles and Practice (Second edition). John Wiley \& Sons Inc.

Toyo Keizai Inc. (2020). CSR Corporate White Paper 2020. Toyo Keizai Inc. In Japanese.

Yamauchi, N. (1997). Non-profit economy: the economics of nonprofit organizations and philanthropy. Nihon Hyoronsha. (In Japanese). 


\section{Authors and Affiliations}

\section{Shusaku Sasaki ${ }^{1,3} \cdot$ Hirofumi Kurokawa $^{2} \cdot$ Fumio Ohtake $^{3,4}$}

1 Faculty of Economics, Tohoku Gakuin University, 1-3-1 Tsuchitoi, Aoba-ku, Sendai, Miyagi 985-8537, Japan

2 School of Economics and Management, University of Hyogo, 8-2-1 Gakuennishi-machi Nishi-ku, Kobe city, Hyogo 651-2197, Japan

3 Center for Infectious Disease Education and Research (CiDER), Osaka University, 2-8, Yamadaoka, Suita City, Osaka 565-0871, Japan

4 Graduate School of Economics, Osaka University, 1-7, Machikaneyama, Toyonaka city, Osaka 560-0043, Japan 